\title{
Effects of Epidermal Growth Factor and Myo-Inositol on Nuclear Configuration and Subsequent Embryonic Development of Sheep Oocytes
}

\author{
Omar Mardenli ${ }^{1, a, *}$, Hadi Awad Hassooni ${ }^{2, b}$, Mahdi Saleh Mohammad Al-kerwi ${ }^{3, c}$ \\ ${ }^{1}$ Department of Animal Production, Faculty of Agriculture, University of Aleppo, 47500 Midyat/Mardin, Turkey \\ ${ }^{2}$ Department of Animal Production, Faculty of Agriculture, University of Al-Muthanna, 66001 Al-Muthanna, Iraq \\ ${ }^{3}$ Department of Animal Production, Faculty of Agriculture, University of Al-Qadisiah, 58001 Al-Diwaniya, Iraq \\ *Corresponding author \\ A R T I C L E I N F O A B S T R A C T \\ Research Article \\ Growth factors and vitamin-like substances have great positive importance in most biological \\ interactions in the cellular level. The addition of these elements in the culture media will increase \\ the yield of the resulting embryos and improve quality. We examined the effects of epidermal \\ growth factor (EGF) and myo-inositol (MI) on meiotic maturation and yields of blastocyst of \\ Awassi sheep oocyte across two experiments. The oocytes obtained were subjected into three \\ treatments: A (without EGF nor MI), B (10 ng/ml EGF + $20 \mathrm{mmol} / \mathrm{l} \mathrm{MI})$ and C (50 ng/ml EGF +40 \\ $\mathrm{mmol} / \mathrm{l} \mathrm{MI}$ ). Oocytes were then cultured in Ham's F-10 medium supplemented with 5\% (v: v) fetal \\ calf serum and $40 \mathrm{ng} / \mathrm{ml}$ follicle - stimulating hormone. In the first experiment, during the 27-h \\ culture period, the oocytes were assessed for germinal vesicle break down, metaphase-I and \\ metaphase-II stages across three-time intervals (9, 21 and 27-h). Results of the experiment showed \\ that EGF and MI enhanced the rates of germinal vesicle break down phase $(1.53 \% ; 27$-h interval; \\ lowest value), metaphase-I (33.87\%; 21-h interval) and metaphase-II (89.23\%; 27-h interval). In \\ the second experiment, the oocytes incubated in treatment $\mathrm{B}$ achieved the highest rates of cleavage \\ $(81.96 \%), 2-8$ cell $(62.35 \%)$ and blastocyst $(45.09 \%)$. It is concluded from the present study that \\ incubating sheep oocytes in culture media containing a cocktail of EGF (10 ng/ml) and MI (20 \\ $\mathrm{mmol} / \mathrm{l}$ ) significantly improves the rates of metaphase-II, fertilization and blastocyst rates. \\ Keywords: \\ Early embryos \\ Epidermal growth factor \\ Myo-inositol \\ Nuclear maturation \\ Sheep
}

(iD) https://orcid.org/0000-0002-6092-7604 (iD) https://orcid.org/0000-0002-6699-9027 https://orcid.org/0000-0003-4688-5548

\section{Introduction}

The end of the twentieth century witnessed remarkable developments in many fields related to animal husbandry, where a complete integration of animal breeding, reproduction, nutrition and housing conditions was observed. Since the emergence of assisted reproductive technologies (ART) to the present days, the technology has sought to increase the yield of in vitro produced embryos by imitating the basic environment within the female genital tract. Growth factors, which are essentially a subset of the cytokines, are among the most important elements added to the culture media in order to support and stimulate growth, differentiation, survival and proliferation of early embryo cells (Arat., 2016). EGF is a secreted peptide found in many fluids in the body, to name but a few, the submaxillary glands of mice (Savage and Cohen, 1972), human's blood and urine (Aybay et al., 2006), intestinal fluid (Nair et al., 2008) and amniotic fluid (Hofmann and
Abramowicz,1990). EGF and its receptors have a wide spectrum in various vital systems and functions within the body, they also play a great supporting role in cell reproduction, division, DNA synthesis, nuclear and cytoplasmic maturation of oocytes, as well as sperm maturation (Yang et al., 2014). Numerous studies have proven the presence of EGF in the follicular fluid of various mammalian ovaries. These studies have also demonstrated the crucial role in the nuclear and cytoplasmic maturation of oocytes through its direct effect on the cumulus cells and their expansion (Gutman et al., 2008; Panigone et al., 2008; Hsieh et al., 2009). MI is a stereoisomer resulted from glucose1-phosphate in a NAD + -catalyzed oxidation/ reduction reaction. In addition to the inclusion of MI in many pathological treatment procedures for humans, MI has a major role in the nuclear maturation of oocytes and subsequent divisions in addition 
to the positive role in lipid metabolism and quality improvement in early embryos (Soltani et al., 2012). Within the scope of assistive reproductive biotechnologies (ART) and in vitro production of embryos, MI is promising due to its important vital role in cell proliferation and regulation of division. On the other hand, both EGF and MI are important additives but both agents lack a major role in oocyte maturation, as some important elements such as follicle - stimulating hormone (FSH) and fetal calf serum (FCS) must be shared in the culture media. Besides, the vital role of $\mathrm{MI}$ in nuclear maturation and support for subsequent embryo division is still not sufficiently studied in most farm animals. Here, the current study targeted the synergistic effect of EGF and MI on nuclear maturation and blastocyst embryo yield by tracing some basic phases of meiosis of sheep oocytes over three-time intervals $(9,21$ and 27 hours) and the effect on the subsequent development of preimplantation embryos.

\section{Materials and Methods}

\section{Reagents}

The chemicals used were from Sigma Chemical Co (St. Louis, USA) unless mentioned otherwise.

\section{Experimental Design}

Two basic experiments were conducted:

\section{Experiment-I}

The experiment was conducted to study the nuclear maturation progression of oocytes treated with different concentrations of EGF ((cat. \#E- 4127) and MI in addition to the control group. The nuclear maturation study included the passage of the oocytes into three main phases: germinal vesicle breaks down (GVBD), metaphase-I (M-I) and metaphase-II (M-II). Groups of oocytes allocated to the different treatments were determined to monitor and follow up the nuclear maturation of the oocyte nuclei across threetime intervals (9,21 and 27- hours).

Experiment-II

In this experiment, all oocytes were destined to evaluate subsequent stages of development, including IVF and cleavage stages down to the blastocyst stage.

The study design falls under the one-factor experimental design (treatment levels) for several traits.

\section{Ovaries and Oocyte Recovery}

Ovaries of Awassi breed ewes were obtained from the slaughterhouses in the city of Aleppo and kept in a physiological saline solution at a temperature of $39^{\circ} \mathrm{C}$. The collected ovaries were transferred to the biotechnology laboratory at the Faculty of Agriculture - the University of Aleppo within a maximum period of 20 minutes. Cumulus oophorus complexes (COCs) were obtained by slicing method of $\geq 2 \mathrm{~mm}$ follicles of Awassi ewes' ovaries (within the breeding season; of $\geq 2$ years old ewes). Only oocytes completely surrounded by unexpanded cumulus cells $(>3$ layers) were used.

\section{EGF and MI Levels Determination}

For all maturation experiments, the levels of EGF and MI were determined according to two increasing shared concentrations (Table 1):

\section{In Vitro Maturation (IVM)}

The resulting COCs specified for the two experiments were washed four times in modified phosphate buffer saline (PBS) supplemented with $40 \mathrm{mg} / \mathrm{L}$ pyruvate, gentamycin and $0.5 \mathrm{mg} / \mathrm{ml}$ bovine serum albumin (BSA); fraction V. COCs were transferred to 4- well plates (groups of up to 30 oocytes) containing $500 \mu \mathrm{l}$ of Ham's F-10 medium supplemented with $5 \%$ (v:v) FCS and $40 \mathrm{ng} / \mathrm{ml} \mathrm{FSH.} \mathrm{The}$ maturation period lasted for $27-\mathrm{h}$ at $39^{\circ} \mathrm{C}$ in an atmosphere of $5 \% \mathrm{CO} 2$ in air with maximum humidity (according to De Oliveira Bezerra et al. (2019) with some modifications).

\section{Assessment of Nuclear Maturation}

Assessment of nuclear maturation was done as described previously (Mardenli, 2020). Briefly, according to the time intervals of incubation for each group of oocytes (experiment I), the oocytes were denuded by repeated pipetting and placed on separate clean dry glass slides. Oocytes were fixed by immersing the slides in a solution of acetic acid and ethanol (1:3). Next, the oocytes were washed with $70 \%$ ethanol and stained with $1 \%$ orcein for 10 minutes. Next, the oocytes were washed with a solution consisted of glycerol, acetic acid and water (1:1:3) and examined under a phase-contrast microscope at x 400 to monitor meiosis phases upon the specified time intervals (Figure 1).

\section{In Vitro Fertilization (IVF)}

As for Experiment II, COCs were washed five times in PBS and three in TALP medium. Next, the COCs were transferred in groups of up to 50 into four -well plates. 250 $\mu \mathrm{l}$ of fertilization medium (TALP) was added to each well contained $10 \mu \mathrm{g}$ heparin-sodium salt $1200 \mathrm{U} / \mathrm{mg}$. Fresh semen was collected from the testis of proven rams by the electric method (Whitlock et al., 2012). Viable and motile sperms were obtained by centrifugation on a Percoll gradient ( $2 \mathrm{ml}$ at $45 \%$ over $2 \mathrm{ml}$ at $90 \%$ ) for $45 \mathrm{~min}$ at 700 $\mathrm{X} \times \mathrm{g}$ at room temperature. The remaining viable spermatozoa at the bottom were collected, washed in TALP and subjected to centrifugation at $100 \mathrm{X} \times g$ for 10 min at room temperature. The resulting aliquots of spermatozoa were diluted in TALP medium to give a concentration of $6 \times 10^{6}$ spermatozoa $/ \mathrm{ml}$. Next, $250 \mu \mathrm{l}$ of the previous suspension was added to each fertilization well to obtain a concentration of $2 \times 10^{6}$ spermatozoa $/ \mathrm{ml}$. Afterwords, COCs were incubated for $24 \mathrm{~h}$ in $5 \% \mathrm{CO}$ in humidified air at $39^{\circ} \mathrm{C}$ (according to De Oliveira Bezerra et al. (2019) with some modifications).

\section{In Vitro Culture (IVC)}

To facilitate the cleavage process, the zygotes were stripped of the cumulus cells by performing vortexing for $2 \mathrm{~min}$ in $2 \mathrm{ml} \mathrm{PBS}$ and washing in PBS + modified synthetic oviduct fluid medium (SOF) three times in each solution. Resulting zygotes were cultured in SOF (1 zygote/ $\mu 1$ medium) in presence of BSA under paraffin oil in a humidified atmosphere of $5 \% \mathrm{CO}_{2}: 5 \% \mathrm{O}_{2}: 90 \% \mathrm{~N} 2$ at $39^{\circ} \mathrm{C}$. Cleavage was assessed at $48 \mathrm{~h}$ of culture. The blastocyst stage was assessed on Days $6-8$ of culture (Figure 2) (according to Vajta et al. (1999) with some modifications). 

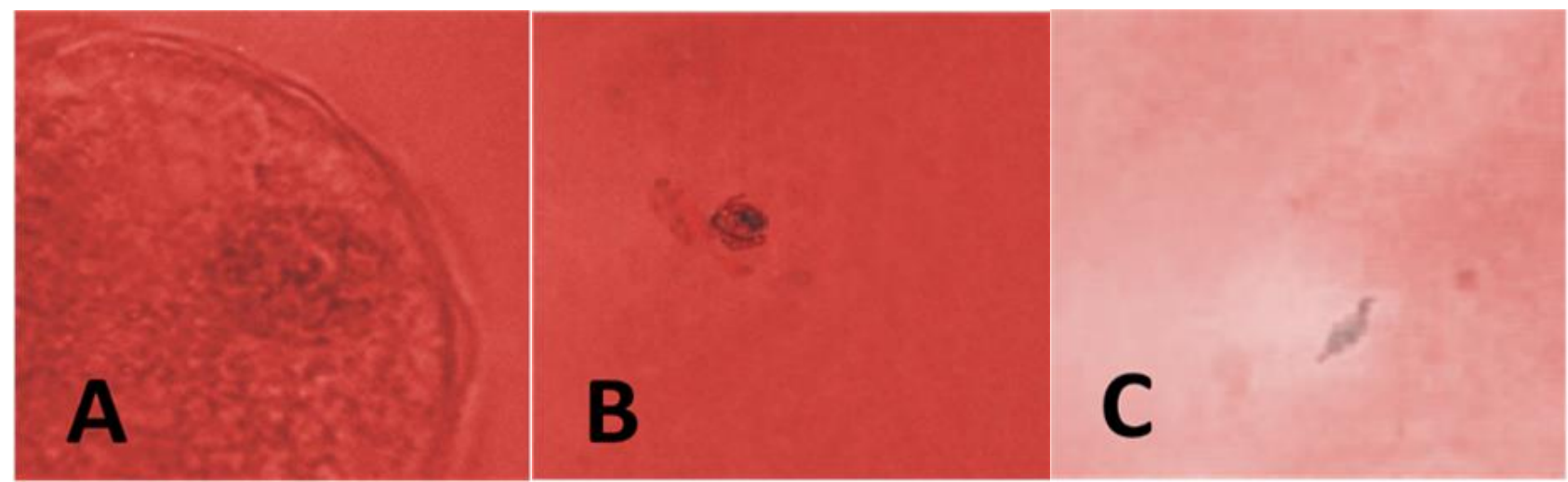

Figure 1. Phases of the nuclear maturation of Awassi sheep oocytes in Experiment I: A: GVBD, B: M-I, C:M-II

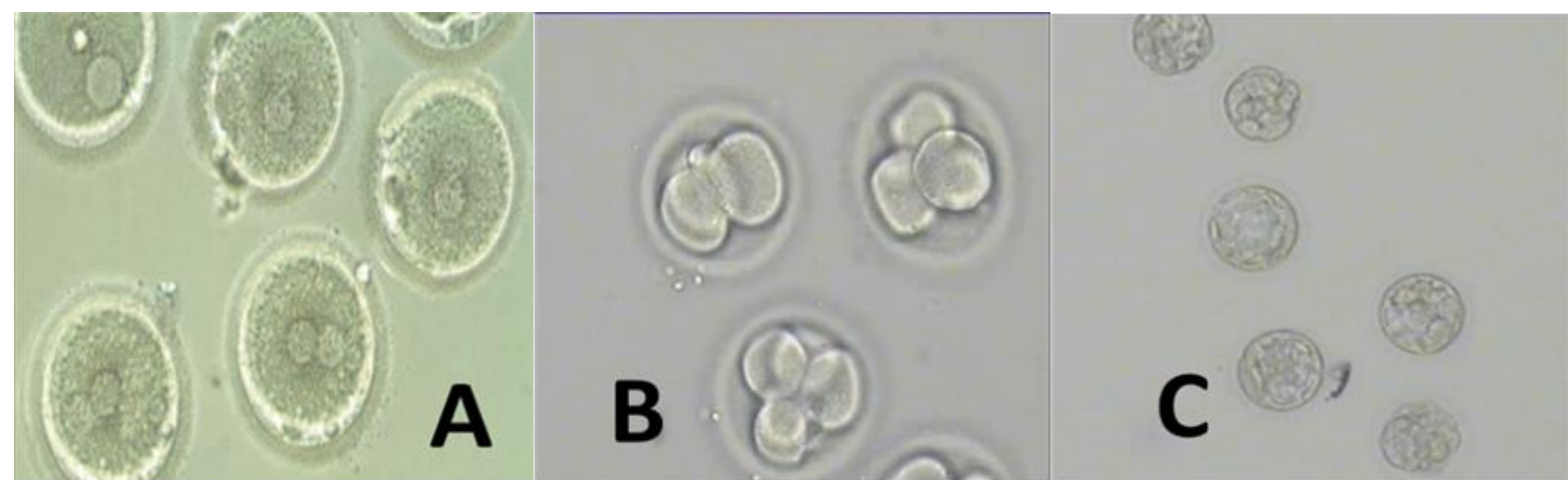

Figure 2. Fertilization and cleavage stages of Awassi sheep early embryos in Experiment II: A: zygotes, B: 2-4 cell stage embryos, C: morula and blastocyst.

\section{Statistical Analysis}

Chi-square of contingency tables was used to analyze the raw data. Fisher's exact test was used to determine significance across various rates. Analysis was done by applying the SAS Institute Inc. (2017) statistical package.

\section{Results}

\section{Experiment $-I$}

Results of the nuclear maturation succession during time intervals 9,21 and 27- $\mathrm{h}$ are presented in Tables 2, 3 and 4. After nine hours of incubation, the type of treatment had a significant effect $(\mathrm{P}=0.03)$ on the oocytes reaching the M-I, the oocytes of treatment B showed a moderate superiority over the rest of the groups (Table 2). In contrast, there were no real differences between the treatment groups at the GVBD phase.

Up to the 21-hour interval, the oocytes of treatment B showed clear superiority across the three phases of nuclear maturation, the rates reached $3.22 \%, 33.87 \%$ and $19.35 \%$, respectively, followed by the incubated oocytes in treatment C $(8.62 \%, 29.31 \%$ and $12.06 \%$, respectively).
In the last time interval of incubation ( 27 - hour), on the same lines, the oocytes of treatment B clearly outperformed the rest of the oocytes of the rest groups in the previous three stages of nuclear maturation. The rate of M-II oocytes reached $89.23 \%(\mathrm{P}=0.03)$ with a difference of $37.62 \%$ and $14.23 \%$ for treatment $\mathrm{A}$ and $\mathrm{C}$, respectively. In contrast, high rates of oocytes were observed in both the GVBD $(\mathrm{p}=0.03)$ and M-I $(\mathrm{p}=0.005)$ in the control group (treatment A), the rates were $11.29 \%$ and $27.41 \%$, respectively (Table 4 ).

\section{Experiment-II}

Results of the cleavage, 2-8 and blastocyst stages are presented in Table 5. The oocytes incubated in B treatment continued to outperform by achieving the highest rate of cleavage $(81.96 \% ; \mathrm{p}=0.0001), 2-8$ cell stage $(62.35 \%$; $\mathrm{p}=0.0001)$ and blastocyst stage $(45.09 \% ; \mathrm{p}=0.0001)$ compared to the remaining two groups (A and $\mathrm{C}$ treatments). As evidenced previously in Experiment -I, the differences between oocytes treatments $\mathrm{B}$ and $\mathrm{C}$ were close in all the studied indicators and did not exceed 3\% (2-8 cell and blastocyst stages) or $7 \%$ (cleavage stage).

Table1. Levels of EGF and MI specified for in vitro maturation of Awassi sheep oocytes

\begin{tabular}{c|cc}
\hline Treatment & EGF $(\mathrm{ng} / \mathrm{ml})$ & MI $(\mathrm{mmol} / \mathrm{l})$ \\
\hline A & 0 & 0 \\
B & 10 & 20 \\
C & 50 & 40 \\
\hline
\end{tabular}


Table 2. The meiotic progression of in vitro matured Awassi sheep oocytes for 9 hours in Ham's F-10 medium across different levels of EGF and MI

\begin{tabular}{|c|c|c|c|c|c|c|c|}
\hline \multirow{3}{*}{ Maturation treatment } & \multirow{3}{*}{ Incubated oocytes No. } & \multicolumn{6}{|c|}{ Phase of nuclear maturation } \\
\hline & & \multicolumn{2}{|c|}{ GVBD } & \multicolumn{2}{|c|}{ M-I } & \multicolumn{2}{|c|}{ M-II } \\
\hline & & No. & $\%$ & No. & $\%$ & No. & $\%$ \\
\hline $\mathrm{A}$ & 61 & 17 & 27.86 & 7 & $11.47^{\mathrm{a}}$ & 0 & 0 \\
\hline B & 63 & 8 & 12.69 & 19 & $30.15^{\mathrm{c}}$ & 0 & 0 \\
\hline $\mathrm{C}$ & 65 & 11 & 16.92 & 13 & $20.00^{\mathbf{b}}$ & 0 & 0 \\
\hline $\mathrm{P}$ & & & & & & & \\
\hline
\end{tabular}

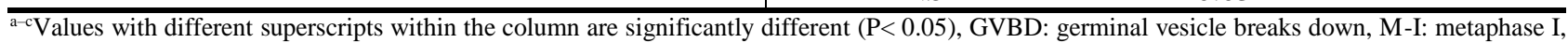
M-II: metaphase II, A: without EGF nor MI, B: $10 \mathrm{ng} / \mathrm{ml}$ EGF + 20 mmol/1 MI, C: $50 \mathrm{ng} / \mathrm{ml} \mathrm{EGF} \mathrm{+40} \mathrm{mmol/1} \mathrm{MI,} \mathrm{NS:} \mathrm{not} \mathrm{significant.}$

Table 3. The meiotic progression of in vitro matured Awassi sheep oocytes for 21 hours in Ham's F-10 medium across different levels of EGF and MI

\begin{tabular}{|c|c|c|c|c|c|c|c|}
\hline \multirow{3}{*}{ Maturation treatment } & \multirow{3}{*}{ Incubated oocytes No. } & \multicolumn{6}{|c|}{ Phase of nuclear maturation } \\
\hline & & \multicolumn{2}{|c|}{ GVBD } & \multicolumn{2}{|c|}{ M-I } & \multicolumn{2}{|c|}{ M-II } \\
\hline & & No. & $\%$ & No. & $\%$ & No. & $\%$ \\
\hline A & 55 & 14 & $25.45^{\mathrm{a}}$ & 6 & $10.90^{\mathrm{a}}$ & 2 & $3.33^{\mathrm{a}}$ \\
\hline B & 62 & 2 & $3.22^{\mathrm{b}}$ & 21 & $33.87^{b}$ & 12 & $19.35^{b}$ \\
\hline $\mathrm{C}$ & 58 & 5 & $8.62^{\mathbf{b}}$ & 17 & $29.31^{\mathrm{b}}$ & 7 & $12.06^{\mathbf{b}}$ \\
\hline $\mathrm{P}$ & & \multicolumn{2}{|c|}{0.001} & \multicolumn{2}{|c|}{0.01} & \multicolumn{2}{|c|}{0.02} \\
\hline
\end{tabular}

$\overline{\mathrm{a}-\mathrm{b}}$ Values with different superscripts within the column are significantly different (P< 0.05$)$, GVBD: germinal vesicle breaks down, M-I: metaphase I, M-II: metaphase II, A: without EGF nor MI, B: $10 \mathrm{ng} / \mathrm{ml} \mathrm{EGF} \mathrm{+} 20 \mathrm{mmol} / \mathrm{l} \mathrm{MI}, \mathrm{C}: 50 \mathrm{ng} / \mathrm{ml} \mathrm{EGF}+40 \mathrm{mmol} / \mathrm{l} \mathrm{MI}$

Table 4. The meiotic progression of in vitro matured Awassi sheep oocytes for 27 hours in Ham's F-10 medium across different levels of EGF and MI

\begin{tabular}{|c|c|c|c|c|c|c|c|}
\hline \multirow{3}{*}{ Maturation treatment } & \multirow{3}{*}{ Incubated oocytes No. } & \multicolumn{6}{|c|}{ Phase of nuclear maturation } \\
\hline & & \multicolumn{2}{|c|}{ GVBD } & \multicolumn{2}{|c|}{ M-I } & \multicolumn{2}{|c|}{ M-II } \\
\hline & & No. & $\%$ & No. & $\%$ & No. & $\%$ \\
\hline A & 62 & 7 & $11.29^{\mathrm{a}}$ & 17 & $27.41^{\mathrm{a}}$ & 32 & $51.61^{\mathrm{a}}$ \\
\hline $\mathrm{B}$ & 65 & 1 & $1.53^{\mathrm{b}}$ & 5 & $7.69^{\mathrm{b}}$ & 58 & $89.23^{b}$ \\
\hline $\mathrm{C}$ & 60 & 2 & $3.33^{b}$ & 8 & $13.33^{\mathbf{b}}$ & 45 & $75.00^{\mathrm{b}}$ \\
\hline $\mathrm{P}$ & & \multicolumn{2}{|c|}{0.03} & \multicolumn{2}{|c|}{0.005} & \multicolumn{2}{|c|}{0.001} \\
\hline
\end{tabular}

${ }^{\mathrm{a}-\mathrm{b}}$ Values with different superscripts within the column are significantly different $(\mathrm{P}<0.05)$, GVBD: germinal vesicle breaks down, M-I: metaphase I, M-II: metaphase II, A: without EGF nor MI, B: $10 \mathrm{ng} / \mathrm{ml} \mathrm{EGF} \mathrm{+} 20 \mathrm{mmol} / \mathrm{l} \mathrm{MI}, \mathrm{C}: 50 \mathrm{ng} / \mathrm{ml} \mathrm{EGF}+40 \mathrm{mmol} / \mathrm{l} \mathrm{MI}$

Table 5. Rates of cleavage, 2-8 and blastocyst stages of in vitro matured Awassi sheep oocytes in Ham's F-10 medium across different levels of EGF and MI

\begin{tabular}{c|ccccccc}
\hline \multirow{2}{*}{ Treatment } & \multirow{2}{*}{ Incubated oocytes } & \multicolumn{2}{c}{ Cleaved oocytes } & \multicolumn{3}{c}{ Embryonic stage } \\
\cline { 2 - 7 } & & & & \multicolumn{2}{c}{$2-8$ cell } & \multicolumn{2}{c}{ Blastocyst } \\
\cline { 2 - 7 } & No. & No. & $\%$ & No. & $\%$ & No. & $\%$ \\
\hline A & 253 & 159 & $62.84^{\mathbf{a}}$ & 109 & $42.57^{\mathbf{a}}$ & 71 & $28.06^{\mathbf{a}}$ \\
B & 255 & 209 & $81.96^{\mathbf{b}}$ & 159 & $62.35^{\mathbf{b}}$ & 115 & $45.09^{\mathbf{b}}$ \\
C & 256 & 192 & $75.00^{\mathbf{b}}$ & 153 & $59.76^{\mathbf{b}}$ & 108 & $42.18^{\mathbf{b}}$ \\
\hline P & & & 0.0001 & & 0.0001 & 0.0001 \\
\hline
\end{tabular}

${ }^{\mathrm{a}-\mathrm{b}}$ Values with different superscripts within the column are significantly different (P< 0.05), A: without EGF nor MI, B: $10 \mathrm{ng} / \mathrm{ml}$ EGF $+20 \mathrm{mmol} / \mathrm{l} \mathrm{MI}$, $\mathrm{C}: 50 \mathrm{ng} / \mathrm{ml} \mathrm{EGF}+40 \mathrm{mmol} / \mathrm{l} \mathrm{MI}$.

\section{Discussion}

The stage of oocyte maturation includes two closely related types, which are cytoplasmic and nuclear maturation. Both types are associated with a set of complex events, many hormones and growth factors that interact according to a timed timeline to ultimately obtain an oocyte capable of fertilization and subsequent division.

Through the results of the first experiment in our current study, it was clear that the matured oocytes in a mixture of EGF and MI outperformed the control group by achieving high rates during their passage to the three stages of nuclear maturity (GVBD, M-I and M-II; Tables 2,3 and 4). The remarkable increase in the oocyte rates reaching $\mathrm{M}-\mathrm{II}$ can be explained by the interconnected role between EGF and MI. EGF, mainly, is found in the ovarian follicle; specifically, in the follicular fluid of different species (Das et al., 1992), while EGF receptors are present on the granulosa layer in preovulatory follicles with high proportions (Feng et al., 1987). EGF and its receptors activate tyrosine kinases and autophosphorylation of the c-terminal- specific tyrosine which in turn receive a variety of signalling molecules harbouring Src homology 2 (SH2) or phosphotyrosine binding (PTB) signals leading to the activation of Ras/Raf/MEK/ERK, JAK/STAT, PI3K/AKT/ mTOR, and P'LC $\gamma /$ PKC signalling pathways that affect cell proliferation and division (Galvez-Contreras et al., 2013). The important role of $\mathrm{MI}$ in nuclear maturation comes through two main mechanisms. In the first mechanism, MI is a major factor in the metabolism of glucose being the second messenger in the act of insulin. MI activate the receptor substrate insulin-1 (IRS-1) and the action of the enzyme phosphatidylinositol- 
3-kinase (PI-3K). Thus, phosphatidylinositol 2-phosphate (PIP2) will be converted into phosphatidylinositol-3phosphate (PIP3) which in turn activates the action of the metabolic pathway protein kinase $\mathrm{B}$ (PKB) leading to glycogen synthesis (Huang et al., 1999). In the second mechanism, MI serves as an activator to the pyruvate dehydrogenase kinase isoenzyme 1 (PDK1), which acts on glucotransporter 4 (GLUT4) allowing glucose molecules to pass into the plasma membrane of the cell (Yoshizaki et al., 2004). Although increasing the concentrations of both EGF and MI (treatment $\mathrm{C}$ ) did not achieve a significant increase in the number of oocytes reaching the M-II or in the yield of embryos reaching the blastocyte stage (Tables 2,3,4 and 5), but the previous results suggest a prolonged effect for both of the studied factors and this may be clarified by the significant increase in previously studied traits. Unfortunately, studies to demonstrate the effect of both EGF and $\mathrm{MI}$ on inducing nuclear maturity are almost very rare; however, comparing with our current results, at a concentration of $1 \mathrm{ng} / \mathrm{ml}$ of EGF, the rates of GVBD and MII were $49.6 \%$ and $64.5 \%$, respectively (follicles with 3-4 $\mathrm{mm}$ of size), as for oocytes derived from follicles with 6-7 $\mathrm{mm}$ of size, the rates were $78.8 \%$ and $92.2 \%$ for both phases, respectively (Procha' Zka et al., 2000). At 40 -h of incubation, our results in the M-II were higher than what de Ávila Rodrigues and Rodrigues (2004) obtained (40\%), meanwhile the GVBD rates were lower $(28 \%)$. Also, our results were somewhat similar to the results of Khatun et al. (2011) at the 24-hour incubation period, as the rates reached $9.3 \%, 19.5 \%$ and $66.3 \%$ for GVBD, M-II and M-II, respectively (oocytes derived from pubertal female goats). In our previous study, at 27-h interval the rates of GVBD ranged between $3.84 \%$ and $3.85 \%$, M-I rates ranged between $7.69 \%$ and $26.92 \%$, while $\mathrm{M}$-II rates ranged between $56.86 \%$ and $84.61 \%$ (Mardenli, 2020).

Likewise, the incubated oocytes in the second and third treatment (treatments B and C) continued the true superiority $(\mathrm{P}=0.0001$; Table 5$)$ in the rates of cleavage, 2-8 cell and blastocyst stages, which is significantly giving a clear explanation of the chronic effect of EGF and MI on the early embryonic stage (Dadi et al., 2007). Not only that, in the literature, most of the studies confirm that the role of EGF is more evident in the stage of fertilization and cell division compared to the oocytes (Vinayak et al., 2018). It has been observed that EGF receptors (EGFR) are located on the cellular membrane of the blastomeres (Wei et al., 2001). Completely in the line, many studies have highlighted the clear effect of MI in supporting early embryo division and increasing zygotes and hatched blastocyst rates (Warner et al., 2003; Colazingari et al., 2014). In a study conducted on bovine oocytes, Zahmatkesh et al. (2018) obtained rates of cleavage and blastocyst of $80.85 \%$ and $37.72 \%$, respectively (10 ng/mL EGF; SOF culture media). In another study (Sirisathien and Brackett, 2003), the rates of 2-4 cell and blastocyst stage reached $56.1 \%$ and $38 \%$, respectively (50 $\mathrm{ng} / \mathrm{mL}$ EGF). Iincubating mouse oocytes at a concentration of $30 \mathrm{mmol} \mathrm{MI}$, the fertilization and 2-cell stage rates reached $67.5 \%$ and $75.9 \%$ respectively (Chiu et al., 2003). Using different concentrations of MI, Soltani et al. (2012) obtained cleavage and blastocyst rates of $66.66 \%$ and $36.36 \%(0.02 \mathrm{~g} / \mathrm{l}), 61.38 \%$ and, $37.33 \%(0.03 \mathrm{~g} / \mathrm{l})$ and $62.59 \%$ and $46.94 \%(0.04 \mathrm{~g} / \mathrm{l})$, respectively.

In light of the results of the current study, and given the functional characteristics of EGF and MI on the level of ovarian activity and oocyte maturation, it is noted that the effect of each of the studied factors is related to a several other different factors. In addition to the thematic role of follicle size factor (Töpfer et al., 2016), both elements are closely related to the volume and nature of the follicular fluid in the follicle, which is determined based on hormonal balance and hormone concentrations regardless of the ovarian follicular wave dynamics through which the dominant follicle is selected so that the oocyte can complete maturation, fertilization and subsequent divisions (Downes and Macphee, 1990; Saito et al., 2000).

More specifically, the dynamics of EGF action appears to be closely related to specific concentrations of FSH in the follicle, as these concentrations are considered a determining factor for the action (Kyung et al., 2002). In turn, parallel studies proved the important role of luteinizing hormone (LH) in stimulating EGF during ovulation (Panigone et al., 2008). In addition to all the previous considerations, the concept of the developmental potential of the oocytes remains the main factor that gives a clear perception of the extent of the influence of the studied factors. The oocytes used in our experiments derived from follicles of different sizes and ovaries of ewes with a large dispersion in the reproductive cycle. Therefore, the diversity in the diameter of the oocytes contributes to a large degree the heterogeneity of the results obtained (O’Shea et al., 2012; Morohaku et al., 2016).

\section{Conclusion}

According to the given results in our study, it can be suggested that enriching culture media with a cocktail of EGF $(10 \mathrm{ng} / \mathrm{ml})$ and MI (20 mmol/l) improves the rates of nuclear maturation phases, cleavage and blastocyst yields of Awassi sheep oocytes derived from follicles of $>2 \mathrm{~mm}$ of size during the breeding season.

\section{References}

Arat S, Caputcu AT, Cevik M, Akkoc T, Cetinkaya G, Bagis H. 2016. Effect of growth factors on oocyte maturation and allocations of inner cell mass and trophectoderm cells of cloned bovine embryos. Zygote, 24(4):554-62. doi: 10.1017/S0967199415000519

Aybay C, Karakus R, Yucel A. 2006. Characterization of human epidermal growth factor in human serum and urine under native conditions. Cytokine, 35(1-2):36-43. doi:10.1016/j. cyto.2006.07.005

Chiu TTU, Rogers MS, Briton-Jones C, Haines C. 2003. Effects of myo-inositol on the in-vitro maturation and subsequent development of mouse oocytes. Human Reproduction, 18(2): 408-416.doi: 10.1093/humrep/deg113

Colazingari S, Fiorenza MF, Carlomagno G, Najjar R, Bevilacqua A. 2014. Improvement of mouse embryo quality by myo-inositol supplementation of IVF media. J Assist Reprod Genet, 31:463-469. doi 10.1007/s10815-014-0188-1

Dadi TD, Li MW, Lloyd KC. 2007. EGF and TGF-alpha supplementation enhances development of cloned mouse embryos. Cloning Stem Cells, 9:315-326. doi:10.1089/ clo.2006.0040

Das K, Phipps WR, Hensleigh HC, Tagatz GE. 1992. Epidermal growth factor in human follicular fluid stimulates mouse oocyte maturation in vitro. Fertil Steril, 57: 895-901. doi: 10.1016/s0015-0282(16)54977-2

De Ávila Rodrigues B, Rodrigues JL. 2004. Effect of two temperatures on in vitro nuclear maturation of bitch oocytes: relation to time culture intervals. R. bras. Ci. Vet, 11(1/2):3739. http://dx.doi.org/10.4322/rbcv.2014.339 
De Oliveira Bezerra A, Nicacio AC, de Oliveira Menezes GR, da Costa Gomes R, da Silva, LOC, de Souza Rocha-Frigoni NA, Mingoti GZ, o da Silva Leão BC, da Costa e Silva EV, Nogueira É. 2019. Comparison between in vitro embryo production using Y-sorted sperm and timed artificial insemination with non-sorted sperm to produce crossbred calves. Animal Reproduction Science, 208: 106101. doi:10.1016/j.anireprosci.2019.06.013

Downes CP, Macphee CH. 1990. Review: myo-inositol metabolites as cellular signals. Eur. J. Biochem, 193: 1-18. doi: 10.1111/j.1432-1033.1990.tb19297.x

Feng P, Knecht M, Catt K. 1987. Hormonal control of epidermal growth factor receptors by gonadotropins during granulosa cell differentiation. Endocrinol, 120: 1121-1126.

Galvez-Contreras AY, Quinones-Hinojosa A, Gonzalez-Perez O. 2013.The role of EGFR and ErbB family related proteins in the oligodendrocyte specification in germinal niches of the adult mammalian brain. Front Cell Neurosci, 7:258. doi:10.3389/fncel.2013.00258

Gutman G, Barak V, Maslovitz S, Amit A, Lessing JB, Geva E. 2008. Regulation of vascular endothelial growth factor-A and its soluble receptor sFlt-1 by luteinizing hormone in vivo: implication for ovarian follicle angiogenesis. Fertil Steril, 89(4):922-926. doi:10.1016/j.fertnstert.2007.03.097

Hofmann GE, Abramowicz JS. 1990. Epidermal growth factor (EGF) concentrations in amniotic fluid and maternal urine during pregnancy. Acta Obstet Gynecol Scand, 69:217-221. doi: 10.3109/00016349009028683

Hsieh M, Musa Zamah A, Conti M. 2009. Epidermal Growth Factor-Like Growth Factors in the Follicular Fluid: Role in Oocyte Development and Maturation. Semin Reprod Med, 27(1): 52-61. doi:10.1055/s-0028-1108010

Huang L, Heimark D, Linko J, Nolan R, Larner J. 1999. A model phosphatase $2 \mathrm{C}$ phosphatase 1 activation cascade via dual control of inhibitor 1 (INH-1) and DARPP-32 dephosphorylation by two inositol glycan putative insulin mediators from beef liver. Biochem Biophys Res Commun, 255:150-156. doi: 10.1006/bbrc. 1999.0111

Khatun M, Bhuiyan MMU, Ahmed JU, Haque A, Rahman MB, Shamsuddin M. 2011. In vitro maturation and fertilization of prepubertal and pubertal black Bengal goat oocytes. Journal of Veterinary Science, 12(1): 75.doi:10.4142/jvs.2011.12.1. 75

Kyung CS, Kyung HS, Ki YT, Jin CC, Kim T, Jae KJ. 2002. The interaction between epidermal growth factor (EGF) and follicular stimulating hormone (FSH) on nuclear maturation of mouse oocytes by using epidermal growth factor receptor (EGFR) inhibitor. Fertility and Sterility, 78: S273-S274. doi:10.1016/s0015-0282(02)03967-5

Mardenli O. 2020. Role of Follicle Size, IGF-I, Glucose and Hormones on Nuclear Maturation Events of Awassi Sheep Oocytes (Ovis aries). ISPEC Journal of Agricultural Sciences, 4(4): 732-746. https://doi.org/10.46291/ISPECJAS vol4iss4pp732-746

Morohaku K, HiraoY, Obata Y. 2016. Developmental competence of oocytes grown in vitro: Has it peaked already? Journal of Reproduction and Development, 62(1): 1-5. doi:10.1262/jrd.2015-148

Nair RR, Warner BB, Warner BW. 2008. Role of epidermal growth factor and other growth factors in the prevention of necrotizing enterocolitis. Semin Perinatol, 32:107-113. doi: 10.1053/j.semperi.2008.01.007

O'Shea LC, Mehta J, Lonergan P, Hensey C, Fair T. 2012. Developmental competence in oocytes and cumulus cells: candidate genes and networks. Systems Biology in Reproductive Medicine, 58(2): 88-101. doi:10.3109/193 96368.2012.656217

Panigone S, Hsieh M, Fu M, Persani L, Conti M. 2008. Luteinizing hormone signaling in preovulatory follicles involves early activation of the epidermal growth factor receptor pathway. Mol Endocrinol, 22(4):924-936. doi: 10.1210/me.2007-0246
Procha' Zka R, Srs` En V, Nagyova E, Miyano T, Flechon, J E. 2000. Developmental regulation of effect of epidermal growth factor on porcine oocyte-cumulus cell complexes: Nuclear maturation, expansion, and F-actin remodeling. Molecular Reproduction and Development, 56(1): 63-73.doi:10.1002/(sici)10982795(200005)56:1<63::aid-mrd8>3.0.co;2-d

Saito H, Kaneko T, Takahashi T, Kawachiya, S, Saito T, Hiroi M. 2000. Hyaluronan in follicular fluids and fertilization of oocytes. Fertil. Steril, 74: 1148-1152. doi: 10.1016/s00150282(00)01586-7

SAS Institute Inc.SAS Institute Inc. 2017. SAS/STAT® 14.3 User's Guide:High-Performance Procedures. Cary, NC 27513 (USA):

Savage RC, Cohen S. 1972. Epidermal growth factor and a new derivative. Rapid isolation procedures and biological and chemical characterization. J Biol Chem 1972: 247:76097611. PMID: 4636326

Sirisathien S, Brackett BG. 2003. TUNEL analyses of bovine blastocysts after culture with EGF and IGF-I. Molecular Reproduction and Development, 65(1): 5156.doi:10.1002/mrd.10263

Soltani L, Kafilzadeh F, Shabankareh HK. 2012. The effect of various concentrations of myo-inositol in culture medium on development of bovine embryos. Iran J Reprod Med, 10 (5): 409-412. PMCID: PMC4169676

Töpfer D, Ebeling S, Weitzel J, Spannbrucker A. 2016. Effect of Follicle Size on In Vitro Maturation of Pre-Pubertal Porcine Cumulus Oocyte Complexes. Reproduction in Domestic Animals, 51(3): 370-377. doi:10.1111/rda.12688

Vajta G, Rindom N, Peura TT, Holm P, Greve T, Callesen H. 1999. The effect of media, serum and temperature on in vitro survival of bovine blastocysts after Open Pulled Straw (OPS) vitrification. Theriogenology, 52: 939-948. doi: 10.1016/S0093-691X(99)00184-3.

Vinayak SG, Meenambigai TV, Mangalagowri A, Reena D, Vijayarani K. 2018. Influence of Epidermal Growth Factor in the In vitro Development of Bovine Preimplantation Embryos. Int. J. Pure App. Biosci, 6(5): 584-589 (2018). doi: http://dx.doi.org/10.18782/2320-7051.6638

Warner SM, Conlon FV, Kane MT. 2003. Inositol transport in preimplantation rabbit embryos: effects of embryo stage, sodium, osmolality and metabolic inhibitors. Reproduction,125(4):479-93. Erratum in: Reproduction 2005, 129(1): 128. PMID: 12683919

Wei Z, Park KW, Day BN, Prather RS. 2001. Effect of epidermal growth factor on preimplantation development and its receptor expression in porcine embryos. Mol Reprod Dev, 60:457-462. doi: 10.1002/mrd.1110

Whitlock BK, Coffman EA, Coetzee JF, Daniel JA. 2012. Electroejaculation increased vocalization and plasma concentrations of cortisol and progesterone, but not substance $\mathrm{P}$, in beef bulls. Theriogenology, 78(4):737-46. doi: 10.1016/j.theriogenology.2012.03.020

Yang J, Okabe H, Monga SP. 2014. Liver Development, Regeneration, and Stem Cells, Pathobiology of Human Disease, Academic Press

Yoshizaki T, Maegawa H, Egawa K, Ugi S, Nishio Y, Imamura T. 2004. Protein phosphatase-2C alpha as a positive regulator of insulin sensitivity through direct activation of phosphatidylinositol 3-kinase in 3T3-L1 adipocytes. J Biol Chem ,279:22715-22726. doi: 10.1074/jbc.M313745200

Zahmatkesh A, Roudbar MA, Joupari MD.2018. A comparative study of EGF effects on in vitro bovine embryo development in monoculture and sequential media. Turk J Biol, 37: 670674. doi:10.3906/biy-1302-74 